\title{
Originals
}

\section{Hepatic and Peripheral Insulin Resistance: A Common Feature of Type 2 (Non-Insulin-Dependent) and Type 1 (Insulin-Dependent) Diabetes Mellitus}

\author{
R.A. DeFronzo, D. Simonson and E. Ferrannini \\ Department of Medicine, Yale University School of Medicine, New Haven, Connectitut, USA
}

\begin{abstract}
Summary. Hepatic glucose production $\left({ }^{3} \mathrm{H}\right.$-glucose technique) and insulin-mediated glucose uptake (insulin clamp technique) were measured in 38 Type 2 (non-insulin-dependent) and 11 Type 1 (insulin-dependent) diabetic patients. Fasting plasma glucose concentration was $8.3 \pm 0.5 \mathrm{mmol} / 1$ in the former, and $9.6 \pm 1.3 \mathrm{mmol} / \mathrm{l}$ in the latter group; the respective fasting plasma insulin levels were $19 \pm 2 \mathrm{mU} / 1(p<$ 0.005 versus $13 \pm 1 \mathrm{mU} / \mathrm{l}$ in 33 age-matched control subjects), and $9 \pm 1 \mathrm{mU} / 1(p<0.01$ versus $14 \pm 1 \mathrm{mU} / 1$ in 36 younger control subjects). In the fasting state, hepatic glucose production was slightly increased $(15 \%, 0.1>p>0.05)$ in the Type 2 diabetic patients and markedly elevated $(65 \%, p<0.001)$ in the Type 1 patients compared with their respective control groups. In both groups of diabetic subjects, the rates of hepatic glucose production were inappropriately high for the prevailing plasma glucose and insulin levels, indicating the presence of hepatic resistance to insulin. Basal plasma glucose clearance was also significantly reduced in both the Type 2 $(34 \%)$ and the Type $1(14 \%)$ diabetic subjects. The fasting plasma glucose concentration correlated directly with hepatic glu-
\end{abstract}

cose production, and inversely with plasma glucose clearance. During the insulin clamp, plasma insulin was maintained at approximately $100 \mathrm{mU} / 1$ in all groups, while plasma glucose was maintained constant at the respective fasting levels. Total glucose uptake was reduced in both the Type $2(4.57 \pm 0.31$ versus $6.39 \pm 0.25 \mathrm{mg} \cdot \mathrm{min}^{-1} \cdot \mathrm{kg}^{-1}$ in the control subjects, $p<0.01)$ and the Type $1(4.77 \pm 0.48$ versus $7.03 \pm 0.22 \mathrm{mg}$. $\min ^{-1} \cdot \mathrm{kg}^{-1}, p<0.01$ ) diabetic patients. Insulin-stimulated glucose clearance was reduced to a similar extent in Type 2 (54\%) and Type 1 (61\%) diabetic subjects, and correlated directly with fasting glucose clearance. These results show that insulin resistance is a common feature of both types of diabetes and can be demonstrated in the basal as well as the insulin-stimlated state. Both hepatic and peripheral resistance to the action of insulin contribute to diabetic hyperglycaemia.

Key words: Type 1 and Type 2 diabetes, insulin resistance, insulin-mediated glucose metabolism, glucose clearance, hepatic glucose production.
The presence of resistance to the glucose-lowering effect of insulin in non-obese, Type 2 (non-insulin-dependent) diabetic patients has been documented with a variety of techniques. They include the insulin clamp technique [1,2], the intravenous insulin tolerance test [3, 4], the combined intravenous insulin-oral glucose tolerance test [5], the forearm perfusion technique [6-8], the quadruple infusion protocol of Ginsberg et al. [9], the somatostatin modification of the quadruple infusion protocol [10], and radioactive glucose isotope methods [11]. Although these studies have established that insulin resistance is quite frequent in Type 2 diabetes, its site (i.e., peripheral or hepatic) has not been determined with certainty. Also controversial is the contribution of glucose over-production to the fasting hyperglycaemia in Type 2 diabetic patients since both raised [12] and normal [13] rates of endogenous glucose output have been reported. Furthermore, it is not clear whether the resistance to exogenous insulin infusion in these patients bears any relation to the insulin resistance present in the fasting state.

The information on insulin-stimulated glucose metabolism in Type 1 (insulin-dependent) diabetic patients is discordant. With the use of the combined intravenous insulin-oral glucose tolerance test, Himsworth and Kerr found that about one-half of their insulin-dependent diabetic patients were resistant to the action of insulin [5]. More recently, Harano et al. [14], using the somatostatin modification of the quadruple infusion technique, have also demonstrated impaired insulin action in most Type 1 diabetic individuals. In contrast, Ginsberg has reported a normal response to insulin in a small group of insulin-dependent diabetic patients [15]. Thus, the prevalence and severity of insulin resistance 
in Type 1 diabetes (independent of insulin antibodies) as well as its tissue localization need to be re-evaluated.

In the present study, we have used the euglycaemic insulin clamp technique in combination with the ${ }^{3} \mathrm{H}$ glucose method to measure rates of glucose production and disposal in both Type 2 and Type 1 diabetic subjects, in the basal postabsorptive state as well as during a sustained increase in the plasma insulin concentration.

\section{Subjects and Method}

\section{Subjects}

The study population consisted of 38 Type 2 and 11 Type 1 diabetic individuals. The mean $( \pm$ SEM) ages of the two groups were $57 \pm 2$ and $34 \pm 3$ years, respectively. Since age per se is known to affect glucose tolerance [16], two groups of control subjects were included. Thirty-six subjects with a mean age ( \pm SEM) of $36 \pm 1$ years served as controls for the Type 1 diabetic subjects, and 33 subjects with a mean age of $55 \pm 2$ years served as controls for the Type 2 diabetic group. The ideal body weights (based on medium frame individuals from the Metropolitan Life Insurance Tables, 1959) of the Type 2 and Type 1 diabetic subjects were $107 \pm 2 \%$ and $101 \pm 4 \%$, respectively. The ideal body weights for the two control groups were $102 \pm 1 \%$ and $104 \pm 1 \%$, respectively.

Eleven of the Type 2 diabetic patients had received previous therapy with oral hypoglycaemic agents but none had received any oral agent or other medication for at least 8 weeks before the study. All of the diabetic patients had fasting plasma glucose concentrations above $6.7 \mathrm{mmol} / \mathrm{I}$ on multiple occasions. The duration of the diabetes in the Type 1 group was $10 \pm 3$ years, and their daily requirement of NPH insulin was $34 \pm 3$ units. One of the Type 1 diabetic subjects was also receiving a morning dose of regular insulin of 10 units. The purpose, nature, and potential risks of the study were explained to all subjects and their written voluntary consent was obtained before participation.

\section{Study Protocol}

All studies were performed in the postabsorptive state at $0800 \mathrm{~h}$ following a 10-12 h overnight fast. In the Type 1 diabetic group, the last dose of NPH insulin was administered $24 \mathrm{~h}$ before the study. Insulinmediated glucose metabolism was quantitated with the insulin clamp technique as described previously [1]. Following a $120 \mathrm{~min}$ (in the normal subjects) or a $180 \mathrm{~min}$ (in the diabetic patients) control period to allow for equilibration of ${ }^{3} \mathrm{H}$-3-glucose, a prime-continuous $(42.6 \mathrm{mU} /$ $\mathrm{m}^{2}$ surface area per min) infusion of crystalline porcine insulin (Eli Lily, Indianapolis, Indiana, USA) was administered for $2 \mathrm{~h}$ to achieve constant physiological hyperinsulinaemia. The plasma glucose concentration was maintained at basal, pre-infusion levels by determination of plasma glucose every $5 \mathrm{~min}$ and the periodic adjustment of a variable infusion of a $20 \%$ glucose solution [1]. Under these steadystate conditions of constant glycaemia, the total amount of glucose taken up by all tissues of the body must be equal to the input of glucose into the body. The input of glucose is, in turn, equal to the sum of the exogenous glucose infusion rate and the rate of residual endogenous (hepatic) glucose production that remains unsuppressed by hyperinsulinaemia. The rate of endogenous glucose production was calculated by subtracting the exogenous glucose infusion rate from the total rate of glucose appearance as measured from the analysis of the ${ }^{3} \mathrm{H}-3$-glucose kinetics (see subsequent description).

In previous studies, we have shown that hyperglycaemia per se will enhance insulin-mediated glucose uptake by a mass action effect [17]. A similar effect of hyperglycaemia has been demonstrated in the presence of basal insulin levels [18]. Therefore, in 11 of the 38 Type 2 diabetic subjects, following the initiation of the insulin infusion, the plasma glucose concentration was allowed to decrease approximately to $6.7 \mathrm{mmol} / 1$ before the exogenous glucose infusion was begun. In addition, five of the young control subjects were restudied under similar conditions of hyperinsulinaemia but after elevation of the plasma glucose concentration to levels similar to those observed in the insulin-dependent diabetic group. This was accomplished by using the hyperglycaemic clamp technique [1] in combination with an exogenous insulin infusion. The exogenous insulin infusion was adjusted empirically, based on knowledge of the plasma insulin response during previous hyperglycaemic clamps performed on the same individuals.

In the control group, the ${ }^{3} \mathrm{H}$-3-glucose (New England Nuclear, Boston, Massachusetts, USA) prime was $25 \mu \mathrm{Ci}$, and the continuous infusion was given at the rate of $0.25 \mu \mathrm{Ci} / \mathrm{min}$. In the diabetic group, the priming dose was increased in proportion to the increase in fasting plasma glucose concentration. Plasma samples for ${ }^{3} \mathrm{H}-3$-glucose specific activity were obtained at 5-10 min intervals for the last $30 \mathrm{~min}$. Following the infusion of insulin, tritiated glucose specific activity was determined at $5-15 \mathrm{~min}$ intervals.

\section{Calculations}

With the insulin clamp, total glucose metabolism during a given time period was calculated by adding the mean rate of endogenous glucose production to the mean glucose infusion rate during the same time period. The glucose clearance was obtained as the ratio of the rate of total glucose metabolism to the steady-state plasma glucose concentration during the insulin clamp. The steady-state plasma glucose and insulin levels were the means of values between $20-120 \mathrm{~min}$.

In the basal state, the rate of endogenous glucose production was calculated by dividing the infusion rate of ${ }^{3} \mathrm{H}-3$-glucose counts by the mean plasma glucose specific activity measured during the last $30 \mathrm{~min}$ of the control period. A steady-state plateau of glucose specific activity was achieved in all diabetic and control subjects before the start of insulin infusion. In the basal state, with constant glycaemia, the rate of glucose appearance equals the rate of glucose disappearance, and therefore provides a measure of basal glucose metabolism. The basal glucose clearance was determined by dividing the infusion rate of ${ }^{3} \mathrm{H}-3$-glucose counts by the steady-state concentration of tritiated glucose counts in plasma. During the insulin infusion, the glucose system is not in steady-state. Therefore, Steele's equations, and a value of 0.65 for the pool fraction [19], were used to compute total rates of glucose appearance. The rate of endogenous glucose production was then obtained by subtracting the exogenous glucose infusion rate from the total rate of glucose appearance. All data are presented as mean \pm SEM. Statistical comparisons were performed by the Student's t-test.

\section{Analytical Procedures}

Plasma glucose concentration was measured by the glucose oxidase method with a Beckman glucose analyzer (Beckman Instruments, Fullerton, California, USA). Plasma insulin concentration was determined by radioimmunoassay using talc to separate bound from free insulin [20]. The coefficients of variation (inter-assay) for our high (100 $\pm 3 \mathrm{mU} / \mathrm{l} ;$ mean $\pm \mathrm{SEM}$ of $10-14$ determinations), medium (48 $\pm 2 \mathrm{mU} / \mathrm{l})$, and low $(8.7 \pm 0.4 \mathrm{mU} / 1)$ quality controls are $9.8 \%$, $12.2 \%$, and $14.0 \%$, respectively. The intra-assay coefficient of variation for the quality controls is $9.8 \%$. Recovery of insulin added to plasma is $103 \pm 3 \%$. In the Type 1 diabetic group, plasma free insulin concentration was determined by radioimmunoassay as above, after treatment of plasma with polyethylene glycol to remove insulin antibodies [21]. Tritiated glucose specific activity was determined as described previously [22]

\section{Results}

\section{Plasma Glucose and Insulin}

The mean fasting plasma glucose concentrations in the control, Type 2, and Type 1 diabetic subjects were 5.1 $\pm 0.1,8.3 \pm 0.5$, and $9.6 \pm 1.3 \mathrm{mmol} / 1$, respectively. 
Table 1. Plasma insulin and glucose concentrations in the basal state and during the insulin clamp studies

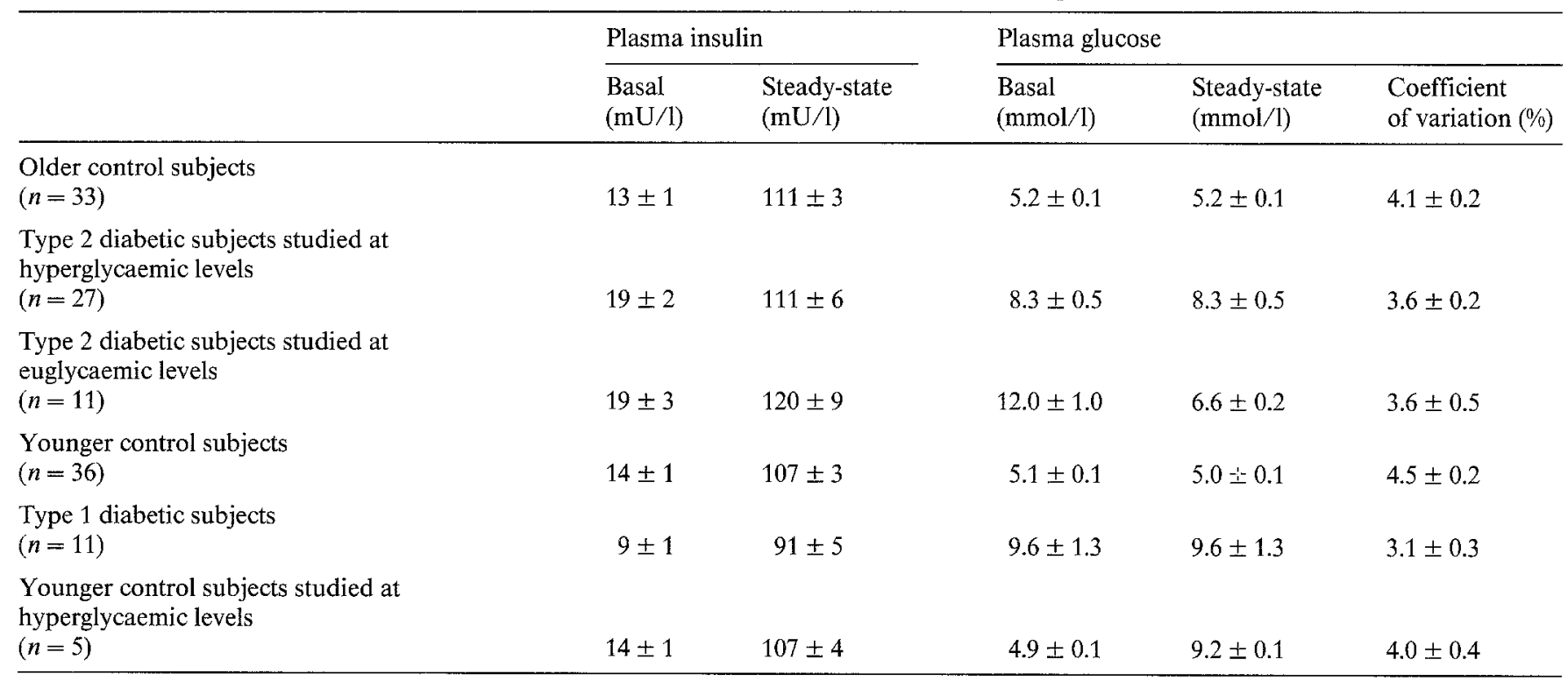

Results are expressed as mean \pm SEM

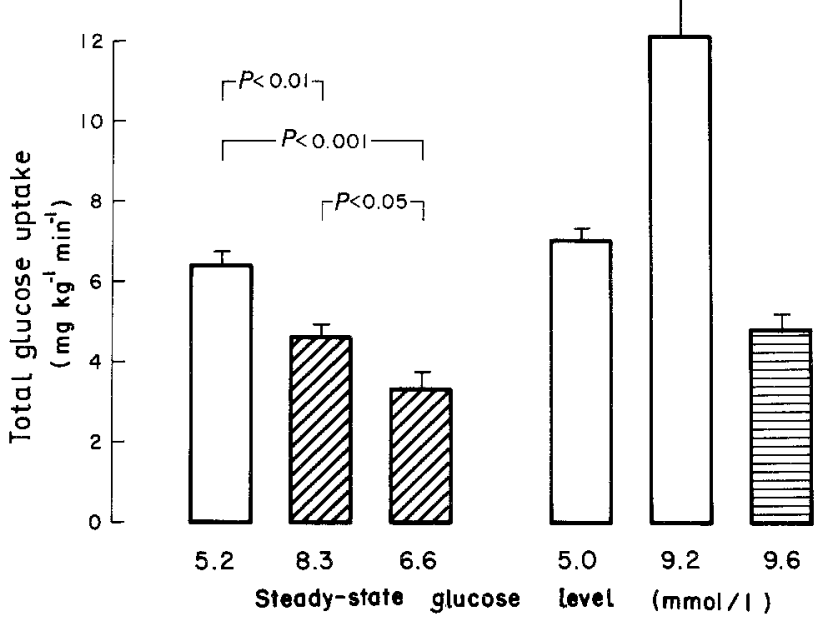

Fig. 1. Total glucose uptake in age-matched control subjects $(\square)$, Type $2(\mathbb{Z})$ and Type 1 diabetic patients (㡺) during a $1 \mathrm{mU} \cdot \mathrm{kg}^{-1}$. $\mathrm{min}^{-1}$ insulin clamp study. The mean steady-state plasma glucose levels during the clamp study for the various experimental groups are given at the bottom of the bars. Data are expressed as mean \pm SEM. The $p$ values refer to unpaired t-test analysis

During the insulin clamp, the plasma glucose was held close to the basal level (Table 1). In the 11 Type 2 diabetic subjects, in whom the plasma glucose concentration was allowed to drop before initiating the exogenous glucose infusion, the mean steady-state glucose level during the clamp study was $6.6 \pm 0.2 \mathrm{mmol} / \mathrm{l}$. In the five control subjects restudied at hyperglycaemic levels, the mean steady-state glucose concentration during the clamp study was $9.2 \pm 0.1 \mathrm{mmol} / \mathrm{l}$. The stability of the plasma glucose concentration during the clamp studies is indicated by the small coefficient of variation (Table 1).

The fasting plasma insulin concentrations in the older control subjects and Type 2 diabetic group were $13 \pm 1$ and $19 \pm 2 \mathrm{mU} / 1$, respectively $(p<0.005)$. In the Type 1 diabetic group, fasting plasma free insulin levels $(9 \pm 1 \mathrm{mU} / \mathrm{l})$ were slightly, though significantly $(p<0.01)$, lower than in the younger control subjects $(14 \pm 1 \mathrm{mU} / 1)$. The steady-state insulin levels during the insulin clamp were similar in all the study groups (Table 1). In the five control subjects restudied under hyperglycaemic conditions, the mean steadystate insulin levels during the euglycaemic (107 \pm $3 \mathrm{mU} / \mathrm{l})$ and hyperglycaemic $(107 \pm 4 \mathrm{mU} / 1)$ clamp studies were virtually identical.

\section{Glucose Metabolism}

During the insulin clamp, the total amount of glucose taken up by the body ( $20-120 \mathrm{~min}$ ) in the 27 Type 2 diabetic subjects studied at their fasting glucose level (4.57 $\left.\pm 0.31 \mathrm{mg} \cdot \mathrm{kg}^{-1} \cdot \mathrm{min}^{-1}\right)$ was reduced by $28 \% \mathrm{com}-$ pared with the age-matched control subjects $(6.39 \pm$ $0.25 \mathrm{mg} \cdot \mathrm{kg}^{-1} \cdot \min ^{-1}, p<0.01$; Fig. 1). The glucose clearance was reduced to an even greater extent $(3.17 \pm$ 0.20 versus $6.93 \pm 0.29 \mathrm{ml} \cdot \mathrm{kg}^{-1} \cdot \mathrm{min}^{-1}, p<0.001$; Fig. 2). In the 11 Type 2 diabetic subjects whose plasma glucose concentration was allowed to decrease to $6.6 \mathrm{mmol} / 1$ before starting the clamp study, the total amount of glucose metabolized $\left(3.32 \pm 0.36 \mathrm{mg} \cdot \mathrm{kg}^{-1}\right.$ - $\min ^{-1}$ ) was significantly less than in the Type 2 diabetic individuals studied at fasting hyperglycaemic levels $(p<0.05)$ or the normal subjects $(p<0.001)$. Only one of the Type 2 diabetic group had a rate of glucose metabolism that was within the mean \pm 1 SEM observed in the control group (Fig. 1). The glucose clear- 


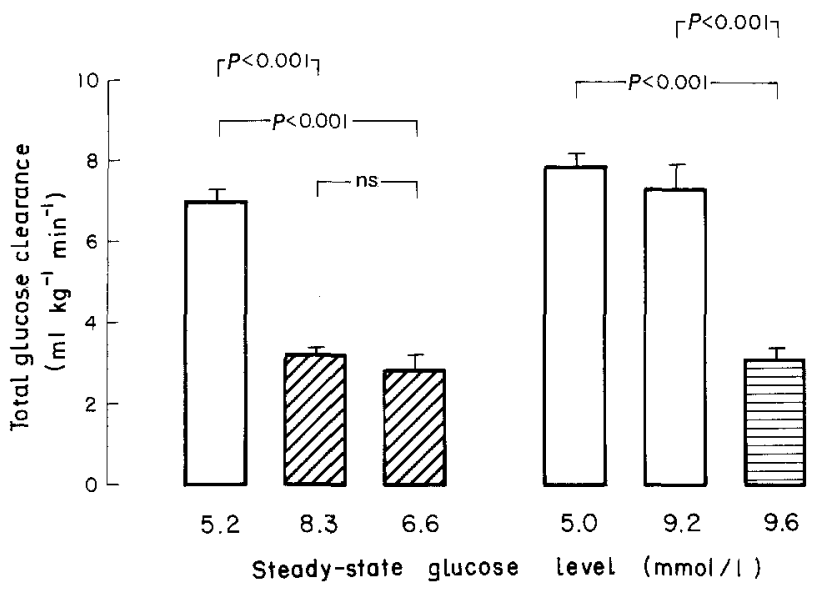

Fig. 2. Total plasma glucose clearance (total glucose uptake $\div$ steadystate plasma glucose concentration) in age-matched control subjects (口), Type 2 ( $\mathrm{kg}^{-1} \cdot \mathrm{min}^{-1}$ insulin clamp study. The mean steady-state plasma glucose levels during the clamp study for the various experimental groups are given at the bottom of the bars. Data are expressed as mean $\pm \mathrm{SEM}$. The $p$ values refer to unpaired $\mathrm{t}$-test analysis

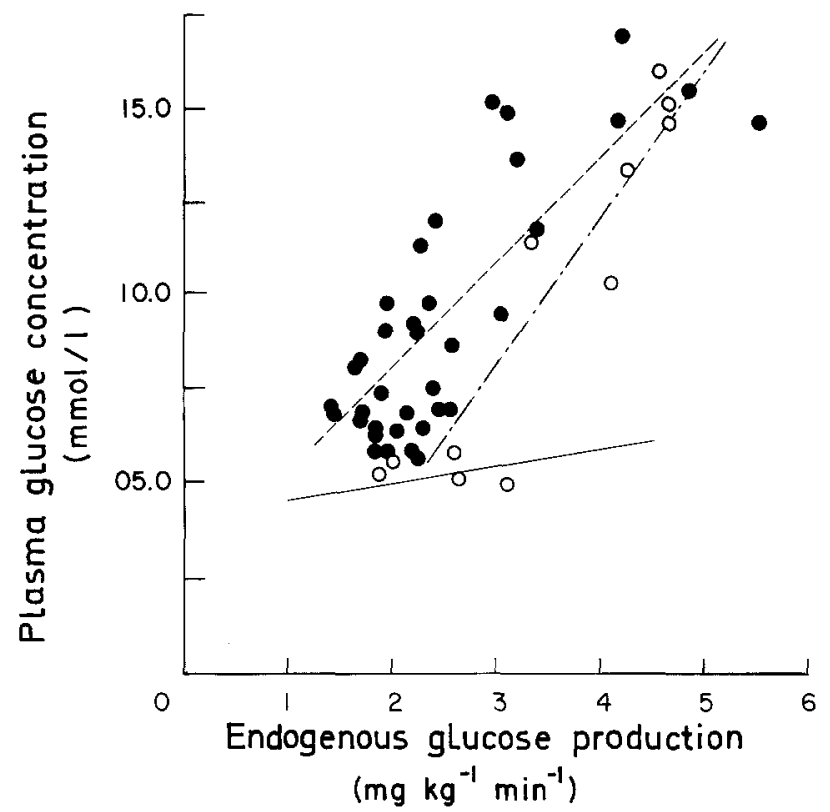

Fig. 3. Relationship between plasma glucose concentration and endogenous glucose production in the fasting state. The solid line is the regression line for the control subjects; Type $2(0)$ and Type $1(O)$ diabetic subjects

ance in the Type 2 diabetic subjects studied at euglycaemic levels $\left(2.83 \pm 0.31 \mathrm{ml} \cdot \mathrm{kg}^{-1} \cdot \mathrm{min}^{-1}\right)$ was similar to that observed in Type 2 diabetic subjects studied at hyperglycaemic levels (Fig.2). In the Type 2 diabetic subjects studied at hyperglycaemic levels, the total amount of glucose metabolized during the insulin clamp was positively correlated $(r=0.50, p<0.01)$ with the fasting plasma glucose concentration. A weak, inverse correlation between fasting plasma glucose and

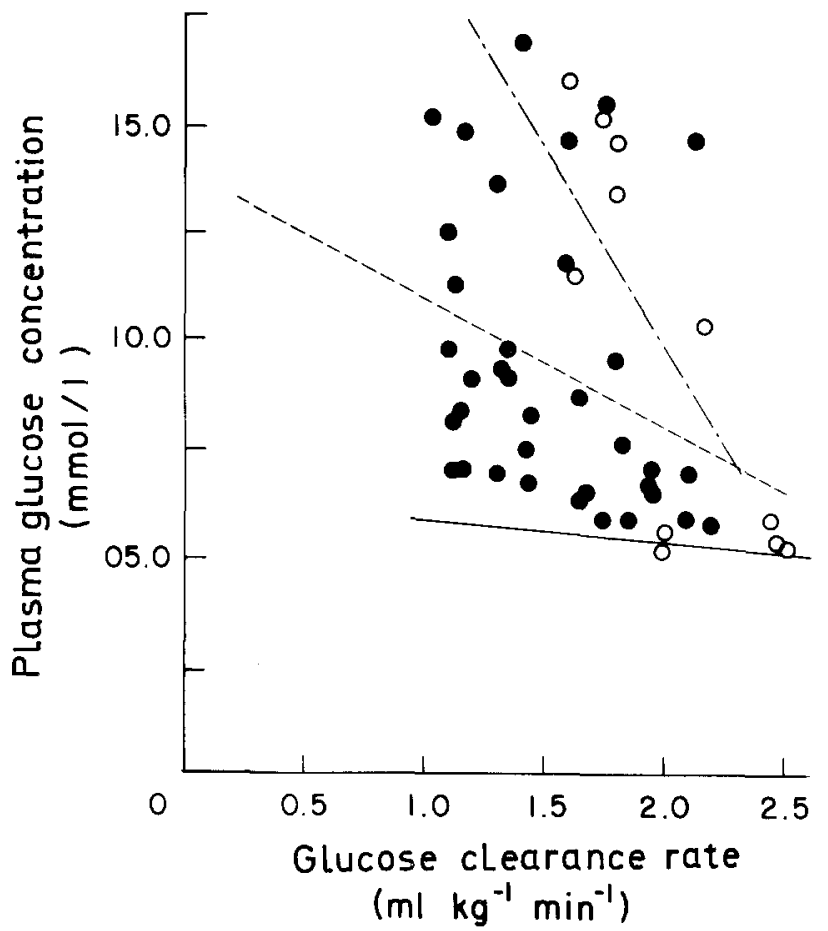

Fig. 4. Relationship between plasma glucose concentration and plasma glucose clearance in the fasting state. The solid line is the regression line for the control subjects; Type $2(0)$ and Type $1(O)$ diabetic subjects

the glucose clearance during the clamp was also found to exist $(r=-0.30,0.10>p>0.05)$.

In the Type 2 diabetic subjects, the total amount of glucose metabolized $(20-120 \mathrm{~min})(4.77 \pm 0.48 \mathrm{mg}$. $\mathrm{kg}^{-1} \cdot \mathrm{min}^{-1}$ ) was also significantly reduced by $32 \%$, compared with control subjects $\left(7.03 \pm 0.22 \mathrm{mg} \cdot \mathrm{kg}^{-1}\right.$ $\cdot \min ^{-1}, p<0.01$; Fig. 1 ). The degree of impairment in glucose metabolism in the Type 1 diabetic subjects is even more striking when compared with the control subjects who were studied at comparable degrees of hyperglycaemia and hyperinsulinaemia $(12.14 \pm 0.96 \mathrm{mg}$ $\left.\cdot \mathrm{kg}^{-1} \cdot \min ^{-1}, p<0.001\right)$. The rate of insulin-mediated glucose metabolism was not significantly different between Types 1 and 2 diabetic subjects. The rate of glucose clearance in the Type 1 diabetic subjects (3.08 $\pm 0.29 \mathrm{ml} \cdot \mathrm{kg}^{-1} \cdot \mathrm{min}^{-1}$ ) was markedly reduced compared with control subjects $\left(7.83 \pm 0.25 \mathrm{ml} \cdot \mathrm{kg}^{-1}\right.$. $\min ^{-1}, p<0.001$; Fig. 2 ) but was not significantly different from the Type 2 diabetic subjects $(3.17 \pm 0.20 \mathrm{ml}$ $\left.\cdot \mathrm{kg}^{-1} \cdot \min ^{-1}\right)$. The total rate of glucose metabolism was positively correlated $(r=0.61, p<0.05)$ with the fasting plasma glucose concentration. In contrast, the glucose clearance was inversely $(r=0.80, p<0.001$ ) correlated with the fasting plasma glucose.

\section{Endogenous Glucose Production}

In the basal, post-absorptive state, plasma glucose concentration, glucose clearance and endogenous glucose 
production were similar in the two control groups. These data could therefore be pooled. A direct correlation was then found to exist between fasting plasma glucose and the rate of endogenous glucose production $(r=0.28, p<0.05)$, whereas the glucose clearance was inversely related to the fasting plasma glucose concentration $(r=-0.33, p<0.05)$.

In the Type 2 diabetic subjects, endogenous glucose production $\left(2.50 \pm 0.15 \mathrm{mg} \cdot \mathrm{kg}^{-1} \cdot \mathrm{min}^{-1}\right)$ was slightly, though not significantly, greater than in the agematched control $\left(2.18 \pm 0.03 \mathrm{mg} \cdot \mathrm{kg}^{-1} \cdot \mathrm{min}^{-1}, 0.1>\right.$ $p>0.05)$. Fasting glucose clearance in the Type 2 diabetic subjects $\left(1.54 \pm 0.05 \mathrm{ml} \cdot \mathrm{kg}^{-1} \cdot \mathrm{min}^{-1}\right)$ was significantly lower than in the control subjects $(2.23 \pm$ $\left.0.03 \mathrm{mg} \cdot \mathrm{kg}^{-1} \cdot \mathrm{min}^{-1}, p<0.001\right)$. A strong, direct correlation existed between fasting plasma glucose concentration and endogenous glucose production $(r=$ $0.80, p<0.001$ ), whereas glucose clearance was weakly related to fasting plasma glucose in an inverse fashion $(r=-0.31,0.1>p>0.05)$ (Figs. 3 and 4).

In the Type 2 diabetic subjects, hepatic glucose production $\left(3.51 \pm 0.04 \mathrm{mg} \cdot \mathrm{kg}^{-1} \cdot \mathrm{min}^{-1}\right)$ was markedly increased compared with age-matched controls (2.13 \pm $\left.0.04 \mathrm{mg} \cdot \mathrm{kg}^{-1} \cdot \min ^{-1}, p<0.001\right)$. Fasting glucose clearance was lower than normal $(2.03 \pm 0.12$ versus $2.35 \pm 0.04 \mathrm{ml} \cdot \mathrm{kg}^{-1} \cdot \mathrm{min}^{-1}$ ). Fasting plasma glucose levels displayed a positive correlation with the rates of glucose production $(r=0.87, p<0.001)$, and a negative correlation with the rates of glucose clearance $(r=$ $0.72, p<0.01$; Figs. 3 and 4 ).

During the clamp, hepatic glucose production in the control subjects declined to $0.43 \pm 0.05 \mathrm{mg} \cdot \mathrm{kg}^{-1}$. $\min ^{-1}$ within $20 \mathrm{~min}$. Over the second hour of the clamp study, heaptic glucose production was suppressed by $>95 \%$ (to $0.08 \pm 0.02 \mathrm{mg} \cdot \mathrm{kg}^{-1} \cdot \mathrm{min}^{-1}$ ). In both Type 2 and Type 1 diabetic subjects, the timecourse as well as the absolute degree of inhibition of hepatic glucose production were similar to those of the respective control groups.

\section{Discussion}

The plasma glucose concentration is the result of two processes, the rate of endogenous glucose production, and the rate of glucose removal by all the tissues in the body. In the post-absorptive state, these two rates are equal, and the plasma glucose level remains relatively constant. In the normal subjects in the present study, we found a direct relationship between fasting plasma glucose levels and the basal rates of endogenous glucose production (Fig. 3), and an inverse relationship between fasting glucose concentration and glucose clearance (Fig. 4). This finding indicates that both hepatic glucose production and glucose clearance are important in maintaining euglycaemia in healthy subjects.

The above relationships were conserved in both Type 1 and 2 diabetic subjects, suggesting that the mechanisms regulating the fasting level of plasma glucose are qualitatively unaltered in these patients. There were, however, several important differences. First, the rates of endogenous glucose production tended to be higher in the Type 2 diabetic subjects, and were definitely increased in the Type 1 diabetic subjects. In fact, in virtutally every diabetic subject, whether Type 1 or Type 2 with fasting plasma glucose levels $>10 \mathrm{mmol} / 1$, endogenous glucose release was elevated in absolute terms. Moreover, even 'normal' rates of glucose production are inappropriately high for the associated degree of hyperinsulinaemia and hyperglycaemia. In the noninsulin requiring diabetic patients, hepatic glucose production was elevated despite significant fasting hyperinsulinaemia. Furthermore, we have shown previously that in normal subjects hyperglycaemia effectively suppresses hepatic glucose production even in the presence of hypoinsulinaemia [23]. Thus, in Type 2 diabetic subjects, the liver is resistant to the restraining effect of both insulin and/or hyperglycaemia on basal glucose release. Likewise, basal glucose production was increased in Type 1 diabetic subjects despite the presence of near normal basal insulin levels and marked hyperglycaemia. In summary, frank over-production of glucose may result when insulin resistance is severe (Type 2 diabetes) or is associated with some degree of hypoinsulinaemia (Type 1 diabetes).

The second major observation was that the plasma glucose clearance in the fasting state was reduced in both Type 2 and Type 1 diabetic subjects. Here, it should be noted that in those diabetics with fasting plasma glucose concentrations $>10-11 \mathrm{mmol} / \mathrm{l}$, the renal threshold for glucose was presumably exceeded and significant glycosuria was present. Since urinary glucose losses were not quantitated in the present study, the calculated rates of plasma glucose clearance must have overestimated tissue glucose clearance by an amount equal to urinary glucose clearance. Consequently, the actual rates of tissue glucose clearance would be even lower than calculated, and their inverse relation to fasting glucose levels stronger. Thus, in Type 1 and Type 2 diabetic individuals, significant insulin resistance was present in the peripheral tissues in the basal state. It is of interest that the basal rates of glucose uptake (= rates of glucose production) were not reduced, since the lower glucose clearance rates were associated with raised plasma glucose levels. Fasting hyperglycaemia, therefore, appears to serve a compensatory function in driving glucose into cells which have a reduced specific capacity to take up glucose. Although it is implicit in the definition of insulin resistance that only insulin-dependent tissues (principally muscle and fat) are responsible for the impaired efficiency of glucose uptake, it cannot be excluded that the insulin-independent tissues (brain, red blood cells, renal medulla, and intestine) may also clear plasma glucose at a reduced rate. 
During the insulin clamp, total glucose uptake was decreased by $30 \%$ in the Type 2 and by $32 \%$ in the Type 1 diabetic groups (Fig. 1) despite their higher plasma glucose levels ( 8.3 and 9.6 versus $5.0 \mathrm{mmol} / 1$ in the controls). The magnitude of this defect is fully appreciated when glucose uptake is 'corrected' for the plasma glucose concentration, i. e., by calculating the glucose clearance. Again, both diabetic groups showed a marked reduction in glucose clearance, and the similarity of this change in the two groups is striking (61\% versus 54\%). Comparing glucose clearance in subjects with widely different plasma glucose levels would provide a biased assessment of the degree of insulin resistance if glucose clearance were itself affected by glucose concentration. That this was not the case in the present studies is shown by two facts. First, when the normal subjects were clamped at similar insulin but higher glucose levels ( 9.2 versus $4.9 \mathrm{mmol} / \mathrm{l})$, glucose clearance was essentially unchanged (Fig. 2), and total glucose uptake was increased in proportion to the hyperglycaemia (Fig.1). Second, and conversely, when Type 2 diabetic subjects with fasting hyperglycaemia were rendered approximately normoglycaemic $(6.6 \mathrm{mmol} / 1)$ and then clamped at insulin levels similar to those of the controls, glucose clearance was similar to that of the Type 2 diabetic subjects studied at hyperglycaemic levels (Fig. 2). Thus, with plasma insulin levels in the high physiological range $(\sim 100 \mathrm{mU} / 1)$, glucose clearance provides a more realistic index of the effect of insulin on glucose uptake by insulin-dependent tissues than does the total amount of glucose metabolized by the body.

During the insulin clamp, hepatic glucose production was inhibited in both Type 1 and Type 2 diabetic patients to the same extent as in normal subjects. The present experiments do not answer the question of whether suppression of hepatic glucose production in diabetic patients might be impaired with small elevations in plasma insulin concentration. Nevertheless, the present results do demonstrate that whatever deficit there might be in the ability of the diabetic liver to shut off glucose release in response to insulin, this can be overcome by higher insulin levels $(\sim 100 \mathrm{mU} / 1)$. The physiological relevance of this observation is that, following the ingestion of a glucose load, portal vein plasma insulin levels rise above $100 \mathrm{mU} / 1$, and remain elevated for a considerable length of time [24]. Therefore, unless the insulin response to glucose administration is severely deficient (as in Type 1 diabetic patients), failure of the liver to inhibit glucose release in response to glucose ingestion is not likely to be a major contributory factor in post-prandial hyperglycaemia.

With regard to the site of insulin resistance under the conditions of an insulin clamp experiment, reduced glucose uptake could occur either in the splanchnic or the peripheral tissues. In previous experiments we have shown that the splanchnic bed is responsible for the uptake of only $5-10 \%$ of an intravenously administered glucose load in normal man [25]. Recent studies in
Type 2 diabetic patients, in which the insulin clamp technique was combined with hepatic vein catheterization, have confirmed this result (R.A.DeFronzo and J.Wahren, unpublished observations). Therefore, the site of the impairment in insulin action demonstrated in the diabetic subjects in this study must reside in peripheral tissues, mostly muscle.

In conclusion, the present results emphasize the importance of insulin resistance in both Type 1 and Type 2 diabetic individuals. This impairment in insulin-action is most evident under hyperinsulinaemic conditions but also manifests itself in the post-absorptive state by an overproduction of glucose by the liver and a decreased rate of glucose clearance by peripheral tissues.

Acknowledgments. We thank L. Mishiwiec for her help in performing the studies, Y.F.Wu for technical assistance, and J.A. Palmieri, secretary-typist. Dr. R. Hendler kindly performed the insulin determinations. This work was supported in part by NIH Research Grant AM 24092, NIH Division of Research Resources Grant RR 00125, and PHS International Research Fellowship 1-F05-TW02716-01.

\section{References}

1. DeFronzo RA, Tobin J, Andres R (1979) The glucose clamp technique. A method for the quantification of beta cell sensitivity to glucose and of tissue sensitivity to insulin. Am J Physiol 237: 214-223

2. Olefsky JM (1980) Insulin resistance and insulin action. An in vitro and in vivo perspective. Diabetes $30: 148-162$

3. Harrison LC, Martin FIR, Melick RA (1976) Correlation between insulin receptor binding in isolated fat cells and insulin sensitivity in obese human subjects. J Clin Invest 58: 1435-1441

4. Beck-Nielsen $H$ (1978) The pathogenic role of an insulin receptor defect in diabetes mellitus of the obese. Diabetes 27:1175-1181

5. Himsworth HP, Kerr RB (1939) Insulin-sensitive and insulin-insensitive types of diabetes mellitus. Clin Sci 4: 119-152

6. Zierler KL, Rabinowitz D (1963) Roles of insulin and growth hormone, based on studies of forearm metabolism in man. Medicine 43: 385-402

7. Jackson RA, Perry G, Rogers J, Advani V, Piklington TRE (1973) Relationship between the basal glucose concentration, glucose tolerance and forearm glucose uptake in maturity-onset diabetes. Diabetes 22: 751-761

8. Butterfield WJH, Whichelow MJ (1965) Peripheral glucose metabolism in control subjects and diabetic patients during glucose, glucose-insulin and insulin sensitivity tests. Diabetologia $1: 43-53$

9. Ginsberg H, Kimmerling G, Olefsky JM, Reaven GM (1975) Demonstration of insulin resistance in untreated adult-onset diabetic subjects with fasting hyperglycemia. J Clin Invest 55: 454-461

10. Harano Y, Ohgaku S, Hidaka $H$, Haneda $K$, Kikkawa $R$, Shigeta $\mathrm{Y}$, Abe H (1977) Glucose, insulin and somatostatin infusion for the determination of insulin sensitivity. J Clin Endocrinol Metab 45: $1124-1127$

11. Forbath N, Hetenyi G (1966) Glucose dynamics in normal subjects and diabetic patients before and after a glucose load. Diabetes 15: 778-789

12. Bowen HF, Moorhouse JA (1973) Glucose turnover and disposal in maturity-onset diabetes. J Clin Invest 52: 3033-3044

13. Manougan E, Pollycove M, Linfoot JA, Lawrence JH (1964) ${ }^{14} \mathrm{C}$ glucose kinetic studies in normal, diabetic, and acromegalic subjects. J Nucl Med 5: 763-795

14. Harano Y, Ohgaku S, Kosugi K, Yasuda H, Nakano T, Kobayashi M, Hidaka H, Izumi K, Kashiwagi A, Shigeta Y (1981) Clinical significance of altered insulin sensitivity in diabetes mellitus as- 
sessed by glucose, insulin and somatostatin infusion. J Clin Endocrinol Metab 52: 982-987

15. Ginsberg HN (1977) Investigation of insulin sensitivity in treated subjects with ketosis-prone diabetes mellitus. Diabetes 26: $278-283$

16. DeFronzo, RA (1979) Glucose intolerance and aging. Evidence for tissue insensitivity to insulin. Diabetes 28: 1095-1101

17. DeFronzo RA, Ferrannini E (1981) Interrelationships between plasma glucose and insulin concentration and glucose uptake in man. Diabetes (in press)

18. Cherrington AD, Williams PE, Harris MS (1978) Relationship between the plasma glucose level and glucose uptake in the conscious dog. Metabolism 27: 787-791

19. Steele R (1959) Influence of glucose loading and of injected insulin on hepatic glucose output. Ann NY Acad Sci 82: 420-430

20. Rosselin GRS, Assan RS, Yalow R, Berson SA (1966) Separation of antibody-bound and unbound peptide hormones labelled with iodine ${ }^{131}$ by talcum powder and precipitated silica. Nature 194: 495-496

21. Kuzuya H, Blix PM, Horowitz DL, Steiner D, Rubenstein AH (1977) Determination of free and total insulin and C-peptide in insulin-treated diabetics. Diabetes 26: 22-29

22. DeFronzo RA, Deibert D, Hendler R, Felig P, Soman V (1979) In- sulin sensitivity and insulin binding to monocytes in maturity-onset diabetics. J Clin Invest 63:939-946

23. DeFronzo RA, Ferrannini E, Wahren J (1978) Regulation of hepatic glucose metabolism by IV insulin and glucose. Diabetes 28 : 379 ( Abstract)

24. Berger W, Goschke H, Moppert J, Kunzli H (1973) Insulin concentrations in portal venous and peripheral venous blood in man following administration of glucose, galactose, xylitol and tolbutamide. Horm Metab Res 5: 4-8

25. DeFronzo RA, Ferrannini E, Hendler R, Wahren J, Felig P (1978) Influence of hyperinsulinemia, hyperglycemia and the route of glucose administration on splanchnic glucose exchange. Proc Natl Acad Sci USA 75: 5173-5177

Received: 27 August 1981

and in revised form: 7 June 1982

Ralph A. DeFronzo, M. D.

Yale University School of Medicine

333 Cedar Street, Room 2074 LMP

New Haven, CT 06510

USA 